\title{
Hipocoagulação: sim ou não?
}

\author{
Anticoagulation: yes or no?
}

Mulher de 38 anos, submetida a cirurgia de substituição valvular aos 32 anos, com colocação de próteses mecânicas mitral e aórtica por doença reumática. Apresentou sempre INR lábil e de difícil controlo. Observada no Serviço de Urgência por cefaleias holocranianas intensas, associadas a hemiparesia esquerda de predomínio braquio-facial e hemianopsia homónima esquerda. Constatada extensa hemorragia intracerebral hemisférica direita, com ruptura para o espaço subdural e subaracnoideu (Figura 1), possivelmente em contexto de sobredosagem de varfarina com INR de 5. Não havia história de traumatismo.

Realizada drenagem cirúrgica e posteriormente craniectomia descompressiva, por hipertensão intra-craniana persistente (Figura 2). Não se conseguiu, no entanto, score da escala de coma de Glasgow superior a 9.

Cerca de 1 mês após a primeira intervenção cirúrgica retomou-se a hipocoagulação com varfarina pelo risco trombótico conferido pelas próteses valvulares. Manteve INR em faixa terapêutica. No entanto, 5 dias depois verificou-se agravamento do estado de consciência e aparecimento de tumefação cefálica temporo-parietal direita. Realizou tomografia computorizada crânio-encefálica que mostrou extensa área hemorrágica no local do anterior sangramento (Figura 3), tendo-se decidido suspender definitivamente a hipocoagulação. Orientou-se a doente para Unidade de Cuidados Paliativos.

Cerca de $20 \%$ das hemorragias cerebrais devem-se ao uso de anticoagulantes e revestem-se por esse motivo de pior prognóstico ${ }^{1}$. Também geram importantes dilemas na gestão do risco trombótico versus hemorrágico, sendo os principais problemas: reiniciar ou não hipocoagulação e quando o fazer ${ }^{1-4}$. Em relação à primeira questão, a decisão dependerá do balanço entre o risco trombótico e hemorrágico de cada doente, enquanto que para o segundo problema parece ser consensual o reinício da hipocoagulação 7 a 14 dias após a hemorragia aguda ${ }^{2,4}$. No caso das próteses valvulares mecânicas, 0 risco de evento trombótico é de cerca de 4\% por ano, aproximadamente equivalente ao risco de recidiva da hemorragia, não havendo portanto consenso na estratégia terapêutica mais correta ${ }^{4}$.

\section{Bibliografia}

1. Dowlatshahi $D$, Butcher $K$, Asdaghi N, et al. Poor prognosis in warfarin-associated intracranial hemorrhage despite anticoagulation reversal. Stroke. 2012; 43: 1812-7.

2. Steiner T. Resumption of oral anticoagulation after warfarin-associated intracerebral hemorrhage: Yes. Stroke. 2011; 42: 3661-2

3. Schulman S. Resumption of oral anticoagulation after warfarin-associated intracerebral hemorrhage: No. Stroke. 2011; 42: 3663-4.

4. Goldstein J, Greenberg S. Should anticoagulation be resumed after intracerebral hemorrhage? Cleveland Clinic Journal of Medicine. 2010; 77: 791-7.

\section{Diagnóstico: Hemorragia intracerebral em contexto de sobredosagem de varfarina}

\footnotetext{
Andreia Vilas-Boas, Filipe Teixeira-Andrade

Servicio de Medicina Interna. Hospital Pedro Hispano. Matosinhos. Portugal

Correspondencia: andreiapvilasboas@gmail.com

Como citar este artículo: Vilas-Boas A, Teixeira-Andrade F

Diagnóstico: Hemorragia intracerebral em contexto de sobredosagem de varfarina Galicia Clin 2014; 75 (1): 44

Recibido: 18/11/2013; Aceptado: 31/01/2014
}

Figura 1. TC-CE da doente à admissão hospitalar mostrando hemorragia aguda corticossubcortical frontoparietal parassagital direita.

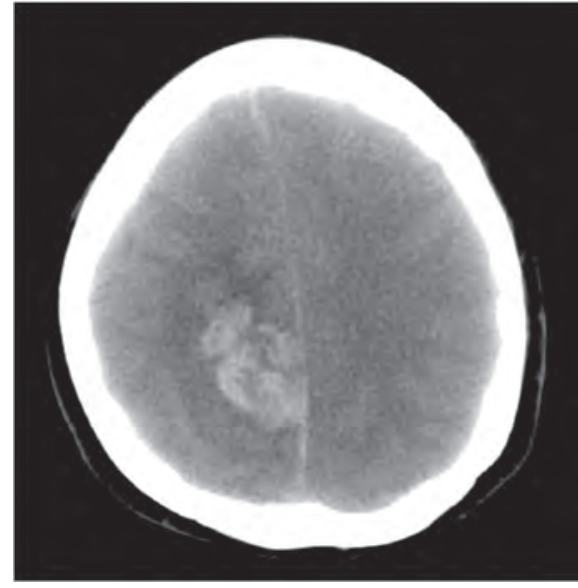

Figura 2. TC-CE pós-craniectomia descompressiva direita com pequeno higroma e mínima quantidade de sangue decantado no corno occipital do ventrículo lateral direito.

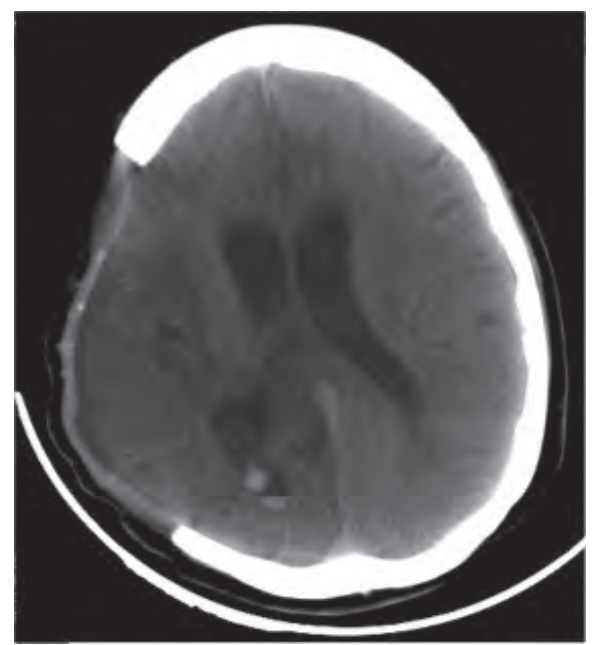

Figura 3. TC-CE de reavaliação após re-introdução de hipocoagulação oral mostrando lesão hemorrágica a deformar levemente a parede do ventrículo lateral direito, associada a hidrocefalia activa.

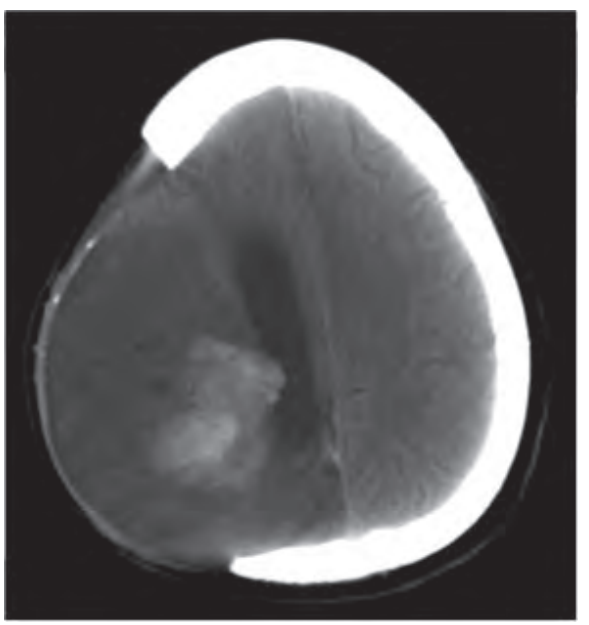

